\title{
UMA ESCOLHA, MÚLTIPLAS MOTIVAÇÕES: O CASO DOS ESTUDANTES DO CURSO DE ARQUIVOLOGIA DA UNIVERSIDADE FEDERAL DE SANTA MARIA
}

\author{
UNA ELECCIÓN, MÚLTIPLES MOTIVACIONES: EL CASO \\ DE LOS ESTUDIANTES DEL CURSO DE ARQUIVOLOGIA DE \\ LA UNIVERSIDAD FEDERAL DE SANTA MARIA
}

\author{
Tatiana Costa Rosa* \\ Rosanara Pacheco Urbanetto**
}

\begin{abstract}
RESUMO:
Introdução: Esta investigação está centrada nas motivações dos estudantes matriculados no primeiro e terceiro semestres, respectivamente, do Curso de Arquivologia da Universidade Federal de Santa Maria.

Objetivos: Estabelecer as motivações dos estudantes pela escolha do Curso de Arquivologia da UFSM; caracterizar os sujeitos, identificar os fatores motivacionais e influenciadores na escolha do curso e identificar as expectativas profissionais dos estudantes em relação ao futuro como arquivistas.

Metodologia: A presente pesquisa caracteriza-se como de cunho descritiva, aliada a um levantamento, e utiliza-se o método qualiquantitativo como abordagem para compreensão, análise e apresentação dos resultados obtidos.

Resultados: A faixa etária dos sujeitos que predominou é 17 a 21 anos, do gênero feminino, residentes na zona urbana. O meio pelo qual a maioria tomou conhecimento do curso foi pela internet. $O$ interesse inicial pela escolha do Curso foi pela baixa nota mínima para ingressar e a listagem das disciplinas que integram o currículo atual, também alguns estudantes foram influenciados por familiares/amigos. Atualmente a maioria considera-se satisfeito com a escolha, permanecem parcialmente com a mesma percepção inicial em relação ao Curso e como perspectivas futuras citam concursos públicos, educação continuada e bom emprego. Os estudantes acreditam que deve haver uma maior divulgação do Curso e dos profissionais que este lança no mercado de trabalho.

Conclusões: Por meio dos resultados obtidos espera-se contribuir com os estudantes do Curso de Arquivologia da UFSM para que conheçam as suas motivações e as dos demais

\footnotetext{
* Mestranda em Letras pela Universidade Federal de Roraima - UFRR. E-mail: tatyrosaa@gmail.com

**Doutora em Líneas de metodología de biblioteconomia e documentación pela Universidade de Salamanca. Professora da Universidade Federal de Santa Maria - UFSM. E-mail: rosanaraurbanetto@gmail.com
} 
Tatiana Costa Rosa, Rosanara Pacheco Urbanetto

Uma escolha, múltiplas motivações: o caso dos estudantes do curso de arquivologia da Universidade Federal de Santa Maria

colegas, e principalmente colaborar com o Núcleo Docente Estruturante (NDE) do Curso de Arquivologia da UFSM encarregado de promover a próxima Reforma Curricular.

Palavras-chave: Curso de Arquivologia. Universidade Federal de Santa Maria. Motivações. Estudantes de Arquivologia.

\section{INTRODUÇÃO}

A Arquivologia, bem como outras ciências, utiliza e apoia-se em elementos de diferentes áreas do conhecimento para formar seu referencial teórico, o que gera uma inter-relação com várias disciplinas, como com a história, o direito, a biblioteconomia e a administração, por exemplo.

Neste sentido, ao observarmos os Cursos de Arquivologia, e em especial o da Universidade Federal de Santa Maria (UFSM), local onde se encontra os sujeitos foco desta investigação, é possível classificá-lo como de caráter generalista. Uma vez que o ensino da Arquivologia na UFSM visa formar arquivistas com maior autonomia, capazes de desempenhar os diferentes papéis ofertados pelo mercado trabalho no meio arquivístico.

No Curso de Arquivologia da UFSM, espera-se formar profissionais capazes de compreender, planejar, executar e avaliar sistemas de arquivos na sua globalidade, atuando assim, como gestores de sistemas de informação, ou mesmo ensinando e perpetuando conhecimentos, como docentes na área.

Contudo, ao investigar pesquisas com esta temática percebe-se que apesar dos estudantes receberem a mesma formação, eles possuem diferentes aspirações profissionais. Acredita-se que este fato está relacionado diretamente com a motivação que estes tiveram no momento de selecionar o curso para estudarem, neste caso $o$ de Arquivologia da UFSM e consequentemente torná-la sua possível profissão.

Campos e Mesquita (2005) desenvolveram um estudo na área da Administração, e constataram que uma das motivações dos estudantes pela escolha do Curso de Administração era a expectativa que alguns alunos tinham em adquirirem conhecimentos suficientes para futuramente abrirem os seus próprios negócios, colaborando assim, com a ideia de que as motivações estão 
Tatiana Costa Rosa, Rosanara Pacheco Urbanetto

Uma escolha, múltiplas motivações: o caso dos estudantes do curso de arquivologia da Universidade Federal de Santa Maria

ligadas às expectativas. Além disto, ao consultar outras pesquisas, como as desenvolvidas por Schein (1990), Dutra (1996), e, Vedoin e Garcia (2010), é possível perceber que há diferentes aspectos que influenciam a escolha por um determinado curso superior. Deste modo, esta investigação está centrada nas motivações dos estudantes matriculados no primeiro e terceiro semestres, respectivamente, do Curso de Arquivologia da UFSM. Tem-se como problema de pesquisa o seguinte questionamento: "Quais são as motivações dos estudantes do Curso de Arquivologia da UFSM ao optarem por este curso?".

Tal questionamento nos remete aos objetivos de pesquisa. Tem-se como objetivo geral: estabelecer quais são as motivações dos estudantes pela escolha do Curso de Arquivologia da UFSM; e como objetivos específicos: caracterizar os sujeitos segundo alguns aspectos; identificar os fatores que podem ter influência na motivação para a escolha do Curso de Arquivologia da UFSM; verificar a influência do Curso de Arquivologia da UFSM na motivação dos estudantes pela escolha do curso; e, identificar as expectativas profissionais que os estudantes possuem em relação ao futuro como profissionais da área arquivística.

Cabe destacar que esta investigação surge no sentido de almejar enriquecer os estudos acerca desta temática, e complementar questionamentos, os quais vêm inquietando as autoras, pois desde o ano de 2012 desenvolvem pesquisas, as quais contemplam o Curso de Arquivologia da UFSM, a formação de seus alunos e as perspectivas de estudantes e arquivistas graduados em Santa Maria, entre elas, as intituladas: Atitudes dos profissionais arquivistas em relação as qualidades consideradas fundamentais: momento de olhar o reflexo no espelho (2012-2014); Perfil e Perspectivas Profissionais dos Acadêmicos do Curso de Arquivologia da UFSM (2013-2013); Da Graduação ao mercado de trabalho: uma reflexão acerca dos egressos do Curso de Arquivologia da Universidade Federal de Santa Maria (2015-2015).

A partir dos resultados obtidos nestas pesquisas acima mencionadas, já foi possível constatar e divulgar junto à comunidade arquivística alguns aspectos e particularidades importantes acerca do Curso de Arquivologia da UFSM, assim como, de seus estudantes e graduados. Entretanto, 
especificamente as motivações dos estudantes pela escolha do curso ainda não foram um aspecto investigado, o que gera uma inquietação por parte das autoras. Desta forma, esta pesquisa é elaborada no intuito de gerar novas reflexões e resultados, podendo vir a complementar os resultados obtidos até então, nas pesquisas realizadas anteriormente pelas autoras.

Além disto, esta investigação justifica-se também pelo fato do Curso de Arquivologia da UFSM estar passando por um período de transformação, pois está em processo de reforma curricular, e com a realização desta pesquisa esperamos contribuir de com os estudantes, e com o Curso em si, que poderá ter um conhecimento das motivações dos seus estudantes matriculados nos semestres letivos iniciais (primeiro e terceiro), especialmente o Núcleo Docente Estruturante (NDE) do Curso de Arquivologia da UFSM encarregado de promover a próxima Reforma Curricular.

\section{A UNIVERSIDADE FEDERAL DE SANTA MARIA, O CENTRO DE CIÊNCIAS SOCIAIS E HUMANAS E O CURSO DE ARQUIVOLOGIA: UM CARÁTER SOCIAL E HUMANO}

De acordo com seu portal eletrônico ${ }^{1}$, a Universidade Federal de Santa Maria (UFSM), foi criada pela Lei ㄲo. 3.834-C de 14 de dezembro de 1960, com a denominação de Universidade de Santa Maria, instalada solenemente em 18 de março de 1961. É uma Instituição pública Federal de Ensino Superior, vinculada ao Ministério da Educação. Localizada no sul do Brasil, na cidade de Santa Maria, no Estado do Rio Grande do Sul. Atualmente a Universidade conta com unidades universitárias descentralizadas, espalhadas pelo estado do Rio Grande do Sul, localizadas nas cidades de Frederico Westphalen, Palmeiras das Missões, Cachoeira do Sul, e Silveira Martins, e conta com oito unidades universitárias centralizadas na cidade de Santa Maria, são elas: Centro de Ciências Naturais e Exatas; Centro de Ciências Rurais; Centro de

\footnotetext{
${ }^{1}$ Disponível em: http://sucuri.ufsm.br/_outros/historico_index.php. Acesso em 20 de Maio. 2017.
} 
Ciências da Saúde; Centro de Tecnologia; Centro de Artes e Letras; Centro de Educação Física e Desportos; Centro de Educação, e o Centro de Ciências Sociais e Humanas, onde encontra-se subordinado o Curso de Arquivologia.

Conforme consta no portal eletrônico do Centro de Ciências Sociais e Humanas (CCSH), ${ }^{2}$ atualmente o Centro conta com os seguintes cursos: Arquivologia; Administração, Ciências Contábeis, Ciências Econômicas; Ciências Sociais; Direito; Filosofia; Comunicação Social (Habilitação em Jornalismo, Relações Públicas e Publicidade e Propaganda), História; Produção Editorial; Psicologia; Relações Internacionais; Serviço Social, e Sociologia. Estes cursos contribuem para que o $\mathrm{CCSH}$ seja considerado um dos maiores Centros de Ensino da UFSM. Tendo como foco essencialmente a capacitação social e humana dos seus estudantes, e colaborando com 0 desenvolvimento da missão que a UFSM possui, de construir, produzir e promover conhecimento por meio de ações de ensino, pesquisa e extensão voltadas para o desenvolvimento regional.

Indo ao encontro com esta perspectiva institucional, o Curso de Arquivologia foi criado pelo Parecer n. 179/76 do Conselho de Ensino Pesquisa e Extensão da UFSM, em 10 de agosto de 1976. Sua criação foi anunciada através da comunicação feita pela Profa. Darcila de La Canal Castelan durante o $3^{\circ}$ Congresso Brasileiro de Arquivologia realizado na cidade do Rio de Janeiro no período de 17 a 22 de outubro de 1976. Contudo, segundo o portal eletrônico do Curso ${ }^{3}$, sua instalação deu-se em março de 1977 com oferecimento de 25 (vinte e cinco) vagas anuais e 04 (quatro) habilitações: Arquivos empresariais, Arquivos escolares, Arquivos históricos e Arquivos médicos. As atividades do Curso iniciaram-se no dia 18 de abril de 1977 com a aula inaugural do Professor José Pedro Pinto Esposel.

Um ano após a aula inaugural, no ano de 1978, foi criado o Departamento de Documentação através da Resolução 001/78/UFSM, com o

\footnotetext{
${ }^{2}$ Disponível em: http://w3.ufsm.br/ccsh/index.php/ccsh/historico . Acesso em: 20 de Maio 2017.

3 Disponível em: http://w3.ufsm.br/prograd/cursos/ARQUIVOLOGIA/APRESENTAcaO.pdf . Acesso em: 20 de Maio 2012.
} 
objetivo de alocar as disciplinas técnicas profissionalizantes para atender as demandas e necessidades específicas do Curso de Arquivologia.

O reconhecimento oficial do Curso deu-se pelo Ministério da Educação e Cultura (MEC), em 1981, através da Portaria n. 076/81/MEC. O Curso estipulava 2.165 horas e 200 horas de estágio supervisionado a serem cumpridas num mínimo de três anos, ou seja, 06 (seis) semestres letivos. Ao longo do tempo, considerando as novas realidades, o currículo do Curso de Arquivologia passou por reformulações, visando sempre à adequação da formação profissional às expectativas institucionais e empresariais. A última reformulação curricular do Curso foi no ano de 2004, todavia, desde o ano de 2010 docentes do Curso vêm desenvolvendo estudos, e debatendo aspectos envolvendo o processo de reforma curricular.

Atualmente o Curso estabelece 2.070 horas obrigatórias, 300 horas de disciplinas complementares e 245 horas de estágio supervisionado, e é o Curso de Graduação da UFSM de menor duração, podendo ser concluído em três anos e meio (sete semestres).

O Curso de Arquivologia da UFSM destina-se a formar um profissional capaz de atuar de forma criativa e eficiente, em atividades que conduzam à conscientização do valor dos arquivos e a preservação dos mesmos. E ainda, que este profissional seja capaz de exercer atividades técnicas e científicas, planejando, organizando e dirigindo arquivos públicos e privados:

O Curso de Arquivologia foi projetado no sentido de atender as solicitações do mercado de trabalho emergente do desenvolvimento sócioeconômico-cultural e em razão da crescente demanda de profissionais habilitados para exercerem atividades técnicas e cientificas em arquivo. (IRION, 1985, p. 99).

Neste Curso da UFSM são graduados bacharéis em Arquivologia, cuja formação acadêmica é pautada numa construção interdisciplinar com a finalidade de preparar um arquivista-cidadão apto para estabelecer uma interrelação com a sociedade em que está inserido. De modo que o estudante ao graduar-se, e tornar-se um profissional arquivista, deve ter em mente a importância e a responsabilidade de seu papel frente a sociedade. Pelo fato da 
Arquivologia, UFSM, CCSH, e o Curso de Arquivologia possuírem um caráter social e humano em sua essência, cabe compreender o que motiva os estudantes - futuros profissionais arquivistas, a optar por este curso e não por outros das demais áreas do conhecimento.

\section{MOTIVAÇÕES E A TEORIA DA EXPECTATIVA}

Segundo Pieron (1977), a motivação pode ser considerada como um conjunto de fatores psicológicos, conscientes ou não, que determinam uma certa conduta por parte de um sujeito.

Já para o pesquisador canadense Victor Vroom (1964), a motivação é percebida como algo de fácil compreensão, mas ainda está longe de ser simples, pelo fato de ser muito particular, envolvendo aspectos íntimos e vivências de cada sujeito. Este pesquisador criou a denominada teoria da expectativa, na qual defende a ideia de que a motivação está intimamente ligada com a escolha individual que cada sujeito pode ter sobre uma determinada atividade. Para Vroom, uma motivação envolve expectativas, valor e instrumentalidade, e surge em um sujeito quando este percebe a possibilidade de obter algum resultado positivo a partir da seguinte equação: Motivação $=$ Expectativa $\mathrm{x}$ Instrumentalidade $\mathrm{x}$ Valor.

Figura 1: Teoria motivacional

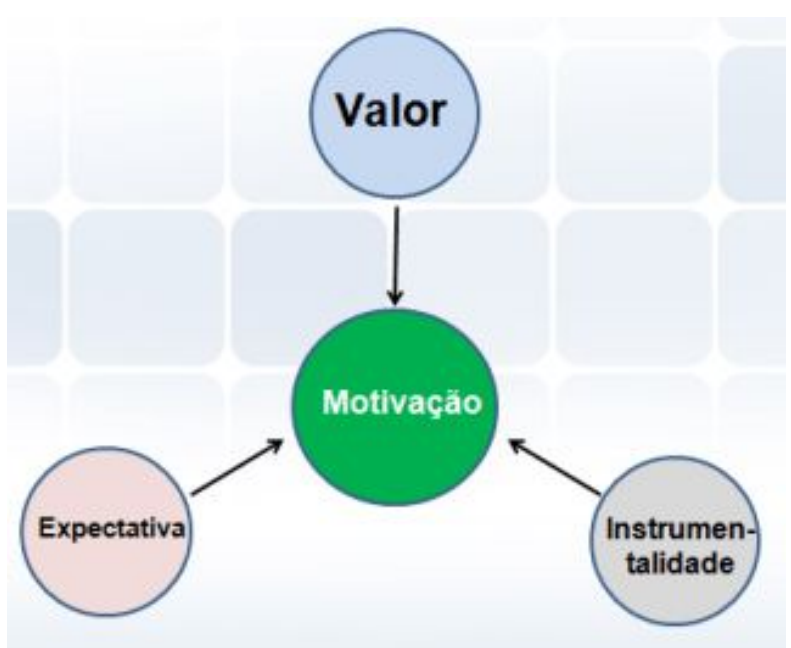

Fonte: Disponível em: <http://jovemadministrador.com.br/teoria-motivacional-de-victor-vroom>. 
Tatiana Costa Rosa, Rosanara Pacheco Urbanetto

Uma escolha, múltiplas motivações: o caso dos estudantes do curso de arquivologia da Universidade Federal de Santa Maria

No que diz respeito à expectativa, Vroom (1964), esclarece que o sujeito analisa as possibilidades com base na percepção que tem de sua própria capacidade, e toma a sua decisão quando se acha capaz de realizar algo, ou não. Caso acredite que não consegue, cria-se uma grande desmotivação antes mesmo de começar a atividade, de modo que o inverso também ocorre se perceber-se capaz, cria-se a motivação, aliada a instrumentalidade e ao valor.

A instrumentalidade de acordo com o pesquisador, nada mais é do que o seguinte questionamento "O que eu ganho com isso?", ou seja, é o instrumento que motiva a recompensa esperada. Enquanto o valor trata-se da balança entre os prós e contras que o sujeito terá ao conquistar algo.

Obviamente as motivações variam de sujeito para sujeito, porém ao ter um conhecimento prévio de algo que se almeja, como um curso de graduação, ou uma profissão, torna-se mais fácil definir as expectativas, instrumentalidades, valores, e consequentemente, as motivações em si. Indo ao encontro com a teoria de Vroom, Dutra (1996, p.43) esclarece que "muitas vezes o sujeito se decide quanto à carreira baseado no estereótipo de sucesso que almeja", contemplando desta forma os três componentes da motivação, defendidos na teoria do pesquisador canadense.

Outro pesquisador que investiga a temática motivação e expectativas, é o autor Edgar Schein, que desenvolveu um estudo no qual visava compreender as motivações e expectativas profissionais de alguns alunos da Sloan School of Management do Massachusetts Institute of Technology (MIT) ${ }^{4}$. Schein acompanhou os estudantes desta faculdade ao longo de doze anos, no período de 1961 a 1973, e observou que a maioria dos estudantes matriculados nos semestres iniciais tinha escolhido um determinado curso pela expectativa de empregos que Ihes poderiam oferecer desafios, maiores salários e maiores responsabilidades. Todavia, do meio para o fim dos cursos, os alunos

${ }^{4}$ A MIT Sloan School of Management é uma das cinco faculdades do Massachusetts Institute of Technology, localizado em Cambridge, no estado norte-americano de Massachussets. 
Tatiana Costa Rosa, Rosanara Pacheco Urbanetto

Uma escolha, múltiplas motivações: o caso dos estudantes do curso de arquivologia da Universidade Federal de Santa Maria

passaram a almejar tipos específicos de trabalho ou responsabilidades, considerando satisfazer suas preferências pessoais, e gerando novas motivações para ingressarem no mercado laboral. Tais preferências que o autor agrupou em categorias, denominando-as âncoras de carreira:

Âncoras de carreira são elementos de nossa realidade que podem determinar as motivações e expectativas sobre determinada ocupação, carreira, empresa ou oportunidade. Refletem ainda, a auto percepção de habilidades, necessidades e valores que se deve possuir profissionalmente [...]. (SCHEIN, 1990, p.65).

As âncoras estão agrupadas em categorias, as quais podem ser utilizadas em estudos para compreender motivações e expectativas de um determinado grupo, ou mesmo individualmente na vida profissional de um sujeito, como uma forma de organizar experiências, identificar áreas de contribuição, gerar critérios para tipos de trabalho e identificar expectativas e motivações que o indivíduo pode determinar conscientemente para si.

\section{CAMINHOS DA PESQUISA}

No entendimento de Minayo (2003, p. 16-18), metodologia da pesquisa é "O caminho do pensamento a ser seguido. Ocupa um lugar central na teoria e trata-se basicamente do conjunto de técnicas a ser adotado para construir uma realidade". Neste sentido, tendo em vista atingir aos objetivos incialmente propostos, adota-se uma metodologia que possibilite desenvolver uma análise ordenada de estudo.

A presente pesquisa caracteriza-se como: de cunho descritiva, aliada a um levantamento, e utiliza-se o método quali-quantitativo como abordagem para compreensão, análise e apresentação dos resultados obtidos.

Optou-se pela pesquisa de caráter descritiva, por esta investigação ir ao encontro com a perspectiva de Gil (2008, p.42), que define: "As pesquisas descritivas têm como objetivo primordial a descrição das características de determinada população ou fenômeno [...] Uma de suas características mais 
Tatiana Costa Rosa, Rosanara Pacheco Urbanetto

Uma escolha, múltiplas motivações: o caso dos estudantes do curso de arquivologia da Universidade Federal de Santa Maria

significativas está na utilização de técnicas padronizadas de coleta de dados, tais como o questionário". De modo que se adotou como instrumento para a coleta de dados um questionário, contendo dez questões: quatro abertas, e seis fechadas. Tal instrumento foi elaborado com base no referencial teórico, visando atingir os objetivos da pesquisa.

Cabe salientar que esta pesquisa trata-se também de um levantamento, o qual Gil (2008, p. 51) aponta: "As pesquisas deste tipo caracterizam-se pela interrogação direta das pessoas cujo comportamento se deseja conhecer". Os sujeitos questionados foram quarenta e quatro estudantes, sendo vinte e seis matriculados no primeiro semestre, e dezoito matriculados no terceiro semestre letivo do ano de 2017, os quais responderam voluntariamente ao questionário, assinando inclusive o Termo de Consentimento Livre e Esclarecido (TCLE), autorizando a divulgação de suas respostas.

Após coletar os dados obtidos por meio das respostas dos estudantes, as autoras realizaram a análise e o tratamento dos resultados, que serão apresentados na sequência, de forma qualitativamente por meio da interpretação dos dados, e quantitativamente por meio de análise numérica. Para uma melhor compreensão comparou-se os dados obtidos com os sujeitos do primeiro semestre juntamente com os do terceiro semestre, e uma melhor visualização de algumas questões optou-se por categorizar as respostas obtidas e apresentar os dados por meio de gráficos.

\section{$5 \quad$ RESULTADOS OBTIDOS}

A autora Isabel Alarcão (1997), afirma que cada ser humano trilha seu próprio percurso de formação, fruto do que é e do que o contexto vivencial the permite que seja, fruto do que quer e do que pode ser. Isto é, são vários aspectos que implicam na trajetória acadêmica e profissional de um sujeito. Partindo desta concepção, aliada ao embasamento dado pela teoria da expectativa anteriormente mencionada, se faz necessário investigar alguns aspectos acerca dos estudantes do Curso de Arquivologia da UFSM, que podem vir a facilitar a compreensão de suas motivações ao escolher este 
Tatiana Costa Rosa, Rosanara Pacheco Urbanetto

Uma escolha, múltiplas motivações: o caso dos estudantes do curso de arquivologia da Universidade Federal de Santa Maria

Curso. Entre os aspectos destaca-se: faixa etária; gênero; região ou zona onde residiam; como tomaram conhecimento do Curso de Arquivologia da UFSM; as motivações em si; influência familiar ou de amigo(s) na motivação; grau de satisfação que o sujeito sente por ter escolhido o Curso de Arquivologia da UFSM; percepções acerca do Curso; e expectativas profissionais em relação ao futuro como arquivista.

Inicialmente investigou-se a faixa etária dos estudantes, as quais foram agrupadas por categorias, conforme é possível observar no gráfico 1 a seguir.

Gráfico 1: Faixa etária.

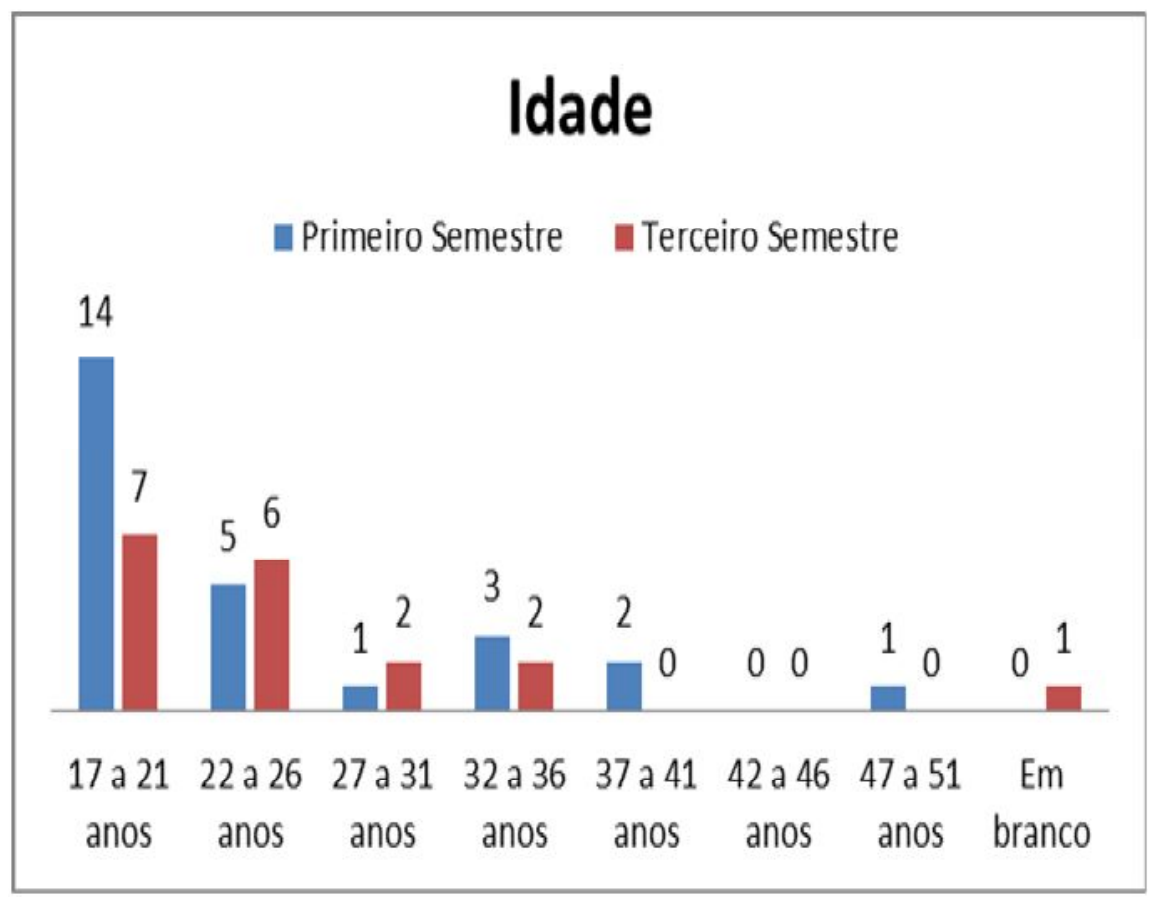

Fonte: as autoras

Pode-se constatar que predominou a faixa etária de 17 a 21 anos, tanto dos sujeitos matriculados no primeiro semestre, quanto no terceiro semestre. Um aspecto que chamou atenção foi 01 sujeito matriculado no primeiro semestre, que se encontra na faixa etária de 47 a 51 anos. O que demonstra que motivações e expectativas independem de idade, e estão intrínsecas em cada sujeito. 
Tatiana Costa Rosa, Rosanara Pacheco Urbanetto

Uma escolha, múltiplas motivações: o caso dos estudantes do curso de arquivologia da Universidade Federal de Santa Maria

Quanto ao gênero foi possível perceber que os estudantes do primeiro semestre são em sua maioria do gênero feminino, sendo 21 mulheres, e 10 homens. Enquanto o terceiro semestre é mais misto, contando com 10 mulheres e 8 homens. Estes dados demonstram uma tradição que vem de muitos anos ${ }^{5}$, visto que a maioria dos estudantes que ingressam no Curso de Arquivologia da UFSM é do gênero feminino.

Já a região ou zona onde em que os estudantes residiram predominantemente durante os estudos anteriores ao ingresso no Curso de Arquivologia da UFSM, não variaram muito. A maioria dos sujeitos, tanto do primeiro, quanto do terceiro semestre afirmaram que já residiam na zona urbana. Sendo que do primeiro semestre 22 sujeitos já residiam em zona urbana, 03 em zona rural, e 01 não respondeu. Enquanto do terceiro semestre 16 sujeitos residiam em zona urbana, e $02 \mathrm{em}$ zona rural.

No que diz respeito à fonte de conhecimento sobre a existência do Curso de Arquivologia da UFSM, optou-se por categorizar as respostas obtidas, visto que algumas respostas foram similares, conforme é possível perceber no gráfico a seguir. Além disto, cabe esclarecer que quanto aos sujeitos do primeiro semestre, cada um respondeu que teve conhecimento da existência do Curso por meio de apenas uma fonte. Enquanto alguns sujeitos do terceiro semestre, responderam mais de uma fonte.

\footnotetext{
5 A autora Kátia Isabeli Melo de Souza, apresenta em seu livro "Arquivista, visibilidade profissional: formação, associativismo e mercado de trabalho", no ano de 2011, um sub capítulo intitulado "Arquivistas segundo o sexo" p. 170. No qual constata e comprova esta tradição da predominância do gênero feminino dentro dos cursos de Arquivologia de todo 0 Brasil.
} 
Gráfico 2: Fonte de conhecimento da existência do Curso de Arquivologia.

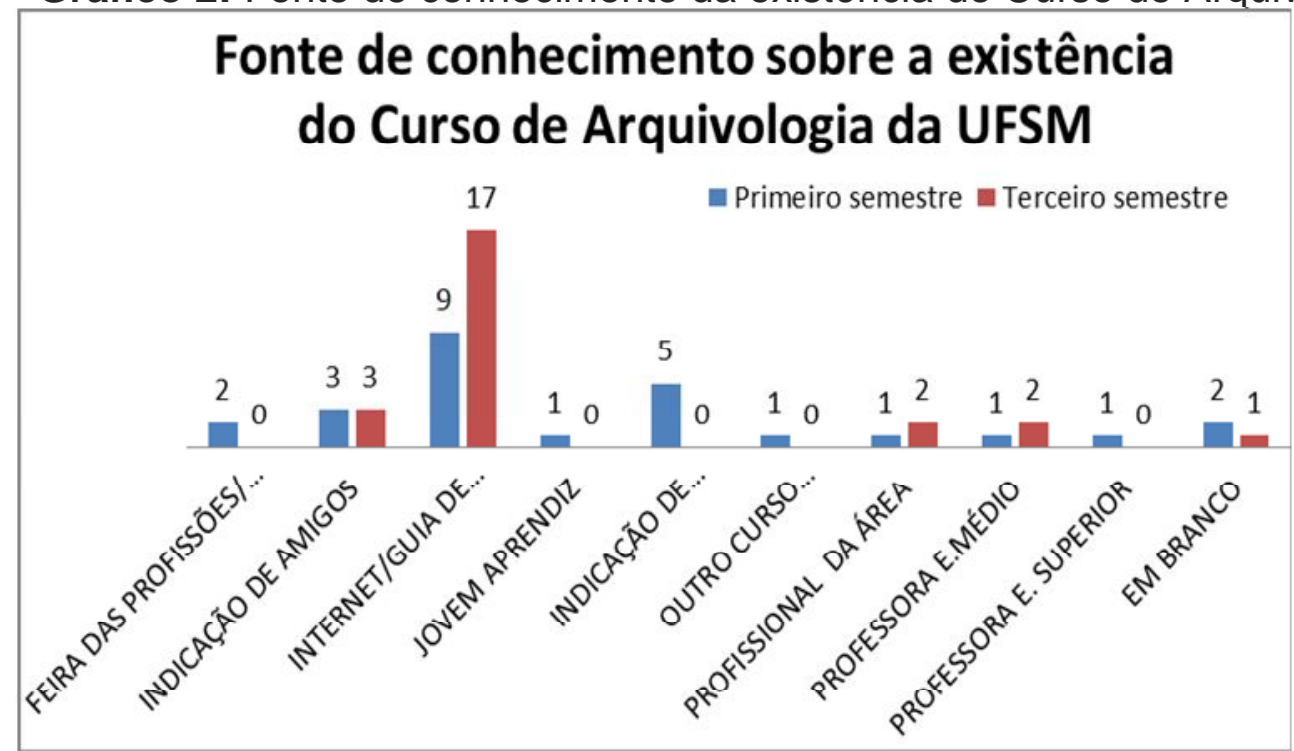

Fonte: As autoras

Entre as fontes pelas quais os estudantes obtiveram conhecimento acerca da existência do Curso de Arquivologia da UFSM, a que mais se destacou em ambos os semestres, foi a categoria internet/guia de $\operatorname{cursos}^{6}$, contando com 09 e 17 sujeitos, respectivamente. Seguida pela categoria indicação de familiares, 05 sujeitos do primeiro semestre, e categoria indicação de amigos, 03 sujeitos de cada semestre.

Quanto à motivação pela escolha do Curso de Arquivologia da UFSM as respostas de ambos os semestres variaram bastante, e por este fato, optou-se por categorizá-las. Conforme é possível observar no gráfico a seguir.

${ }^{6}$ Esta categoria contemplou respostas como: portal eletrônico da UFSM, portal eletrônico do Curso de Arquivologia da UFSM, e portal eletrônico do SISU. 
Tatiana Costa Rosa, Rosanara Pacheco Urbanetto

Uma escolha, múltiplas motivações: o caso dos estudantes do curso de arquivologia da Universidade Federal de Santa Maria

Gráfico 3: Principais motivações para cursar Arquivologia

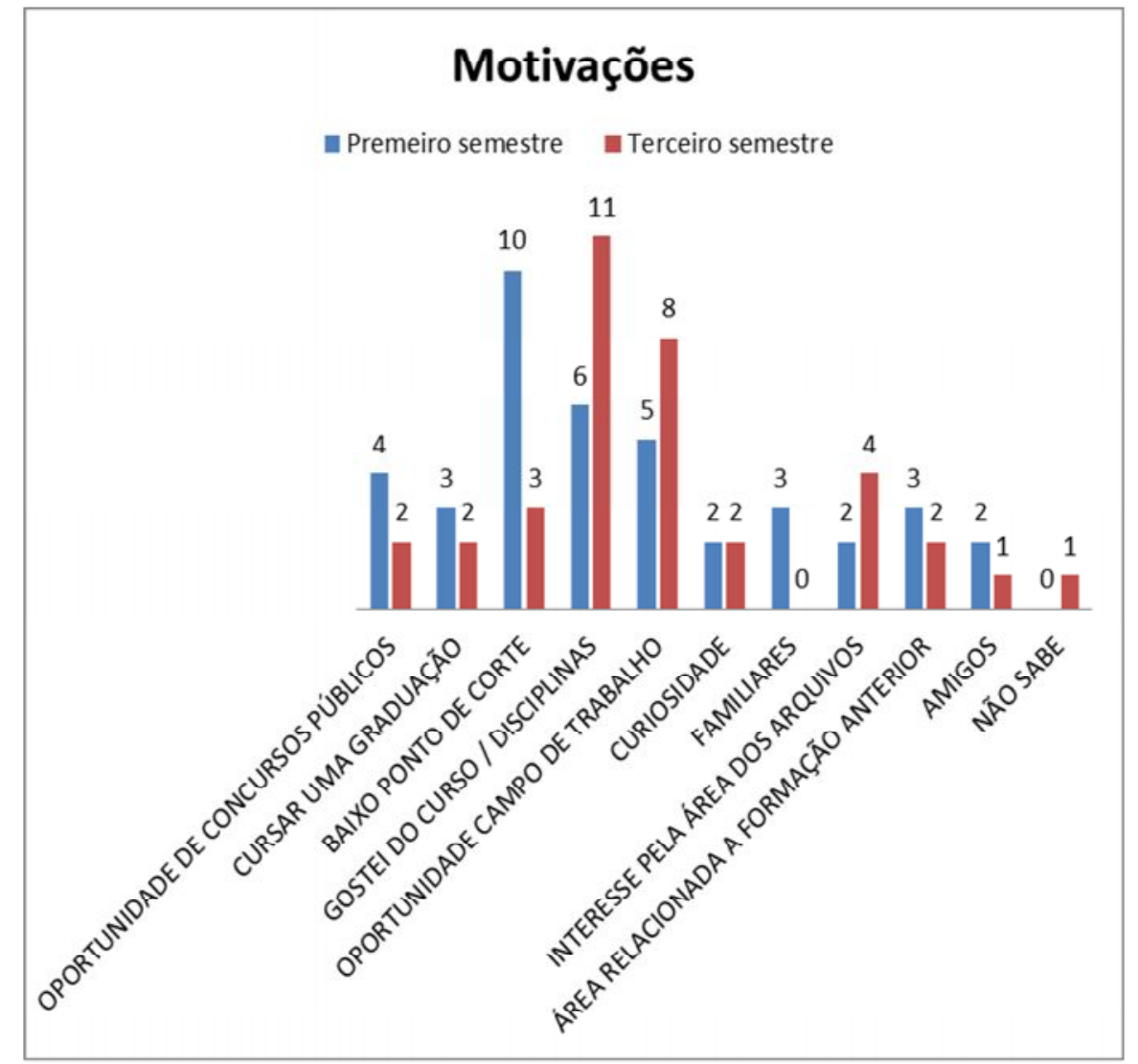

Fonte: As autoras

Os dados relacionados à motivação ao serem analisados, despertaram certa preocupação, especialmente ao que diz respeito aos estudantes do primeiro semestre, os quais em sua maioria demonstram que este aspecto está relacionado ao baixo ponto de corte (nota mínima para ingressar no ensino superior). Seguido, entretanto, pelas respostas dos sujeitos de ambos os semestres, que citaram como motivação que gostaram da listagem de disciplinas apresentadas na página da UFSM em relação ao Curso de Arquivologia, e outros afirmaram que foram motivados pelo fato de perceberem que o Curso oferece mais oportunidades de colocação mo mercado de trabalho ao concluí-lo, diferenciando-se de outras profissões mais (re) conhecidas.

Schein (1990), conclui que motivações e expectativas profissionais geralmente estão aliadas a alguns fatores, entre eles, as influências passadas por meio de experiências pessoais de familiares, amigos, ou pessoas próximas de um determinado sujeito. Esta lógica de Schein vai ao encontro com as 
Tatiana Costa Rosa, Rosanara Pacheco Urbanetto

Uma escolha, múltiplas motivações: o caso dos estudantes do curso de arquivologia da Universidade Federal de Santa Maria

respostas dos sujeitos. Ao serem questionados com relação a ter algum familiar, amigo ou pessoa próxima que cursou Arquivologia, a maioria dos estudantes, sendo 19 sujeitos do primeiro semestre, e 12 do terceiro semestre, responderam não ter familiares ou amigos no meio arquivístico. No entanto, 07 sujeitos do primeiro, mencionaram ter familiares e amigos arquivistas, e afirmaram que estes tiveram influência em suas motivações ao escolher pelo Curso de Arquivologia da UFSM. Já 06 sujeitos do terceiro semestre citaram que possuem familiares e amigos no meio arquivístico, destes, 04 consideram que isto foi um agente motivador na escolha pelo Curso, todavia, 02 sujeitos afirmaram que este fator não teve nenhuma influência em suas motivações.

No que diz respeito ao grau de satisfação com o Curso de Arquivologia da UFSM pode-se perceber que a maioria dos estudantes, tanto do primeiro, quanto do terceiro semestre, consideram-se satisfeitos, como é possível perceber no gráfico 4 a seguir.

Gráfico 4: Grau de satisfação dos acadêmicos pelo curso

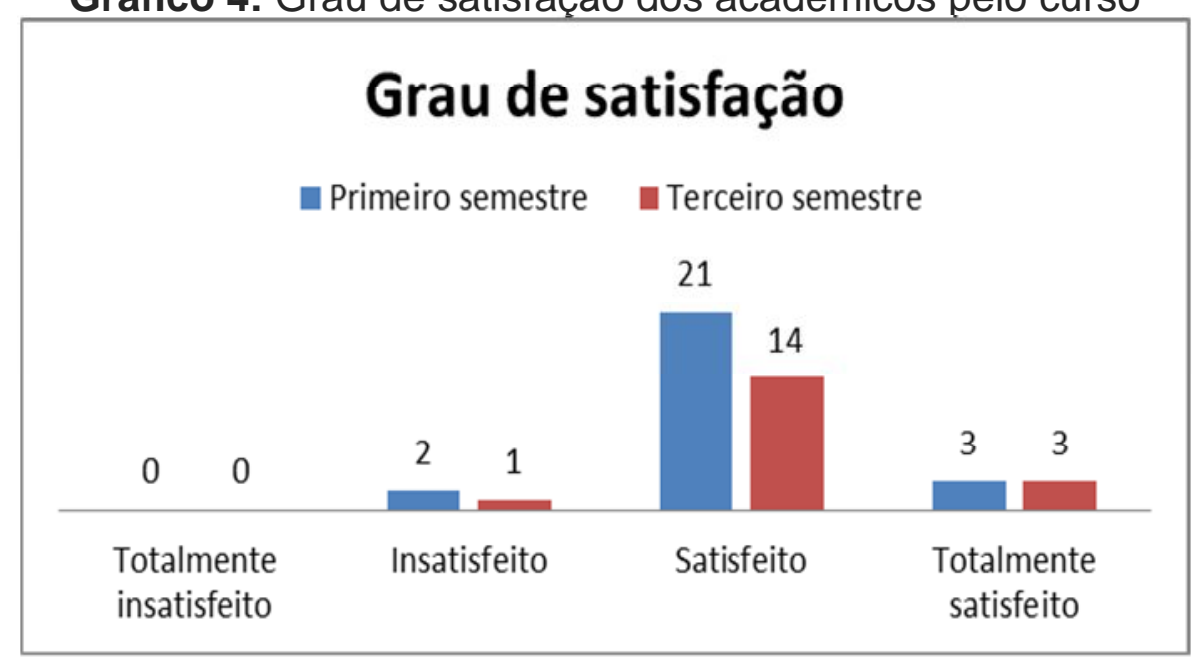

Fonte: As autoras

No total de 26 sujeitos do primeiro semestre, 21 consideraram-se satisfeitos com o Curso. Contudo, 02 consideraram-se insatisfeitos, e 03 totalmente insatisfeitos. Enquanto dos 18 sujeitos do terceiro semestre, 14 afirmaram estar satisfeitos, 01 insatisfeito, e 03 totalmente insatisfeitos. Cabe salientar que os 21 sujeitos do primeiro semestre, estão apenas a 05 meses 
Tatiana Costa Rosa, Rosanara Pacheco Urbanetto

Uma escolha, múltiplas motivações: o caso dos estudantes do curso de arquivologia da Universidade Federal de Santa Maria

cursando Arquivologia na UFSM, enquanto os 14 sujeitos do terceiro semestre, que afirmaram o mesmo, estão cursando há 01 ano.

Quanto à percepção que os sujeitos tinham sobre o Curso de Arquivologia antes de ingressar, pode-se constatar que a maioria de ambos os semestres permanecem parcialmente com a mesma percepção, seguidos pelos que afirmaram ainda terem a mesma visão sobre o Curso. Apenas 02 sujeitos do primeiro semestre, e 03 sujeitos do terceiro semestre, não permanecem com a mesma, como é possível observar no gráfico 05 a seguir.

Gráfico 5: Percepção do curso antes de ingressar

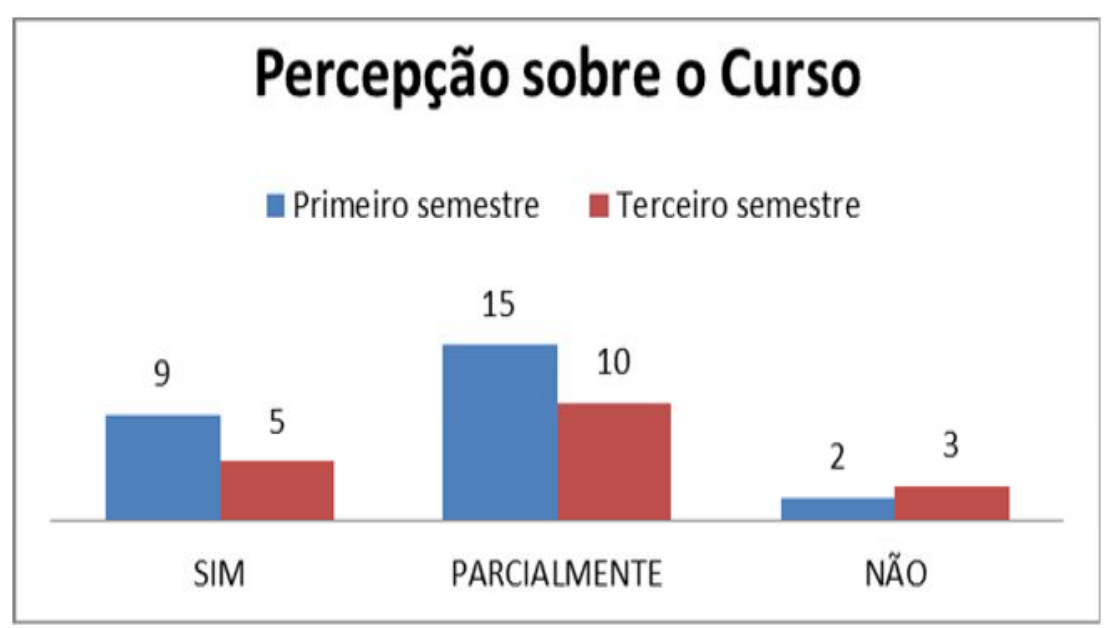

Fonte: As autoras

No que diz respeito às mudanças que os estudantes acreditam que o Curso de Arquivologia da UFSM poderia fazer para motivar mais sujeitos a ingressar nele, as respostas assinaladas foram bem diversificadas, conforme é possível perceber na tabela 1 abaixo, onde consta o número de sujeitos do respectivo semestre; possíveis aspectos que poderiam ser modificados; e o grau de importância que consideram cada aspecto a ser modificado. 
Tatiana Costa Rosa, Rosanara Pacheco Urbanetto

Uma escolha, múltiplas motivações: o caso dos estudantes do curso de arquivologia da Universidade Federal de Santa Maria

Tabela 1: Aspectos devem ser modificados para motivar a escolha do curso de Arquivologia.

\begin{tabular}{|c|c|c|c|c|c|c|c|c|}
\hline & \multicolumn{2}{|c|}{ NENHUMA } & \multicolumn{2}{|c|}{ POUCA } & \multicolumn{2}{|c|}{ MÉDIA } & \multicolumn{2}{|c|}{ MUITA } \\
\hline & $\begin{array}{l}1^{\circ}= \\
\text { Sem }\end{array}$ & $\begin{array}{l}30 \\
\text { Sem }\end{array}$ & $1^{\circ} \mathrm{Sem}$ & $3^{\circ}$ Sem & $\begin{array}{l}10 \\
\text { Sem }\end{array}$ & $3 \circ$ Sem & $1^{\circ} \mathrm{Sem}$ & $\begin{array}{l}30 \\
\text { Sem }\end{array}$ \\
\hline No conteúdo das disciplinas & 2 & 2 & 9 & 5 & 8 & 9 & 6 & 1 \\
\hline Na metodologia de ensino & 2 & 0 & 6 & 6 & 10 & 8 & 3 & 5 \\
\hline Na forma de avaliação & 4 & 1 & 10 & 10 & 7 & 3 & 1 & 3 \\
\hline Nas relações aluno/ professor & 3 & 3 & 11 & 7 & 7 & 4 & 2 & 3 \\
\hline $\begin{array}{l}\text { Na interação entre teoria e } \\
\text { prática }\end{array}$ & 1 & 0 & 5 & 3 & 10 & 5 & 8 & 6 \\
\hline Na divulgação do Curso & 0 & 0 & 1 & 6 & 7 & 7 & 18 & 9 \\
\hline $\begin{array}{l}\text { Na divulgação da } \\
\text { profissãoarquivista }\end{array}$ & 0 & 0 & 3 & 1 & 4 & 4 & 18 & 11 \\
\hline $\begin{array}{l}\text { Na realização de eventos que } \\
\text { contemplem a } \\
\text { comunidade/sociedade }\end{array}$ & 0 & 1 & 5 & 1 & 8 & 9 & 12 & 7 \\
\hline
\end{tabular}

Fonte: As autoras

Entre as principais mudanças que os estudantes apontaram que o Curso poderia adotar as que mais se destacaram tanto no primeiro, quanto no terceiro semestre foram os aspectos que envolvem a divulgação do Curso de Arquivologia, e a divulgação da profissão arquivista, seguidas pela realização de eventos que contemplem a comunidade/sociedade. O que pode servir como motivação ao Curso, no sentido de desenvolver um estudo que mais aprofundado acerca desta questão.

Quanto às expectativas profissionais, em relação ao futuro como arquivista, devido às variadas respostas obtidas, e pelo fato de algumas compreenderem mais de um item de expectativa profissional, optou-se por categorizá-las, conforme é possível observar na tabela a seguir.

Tabela 2: Expectativas profissionais

\begin{tabular}{|l|c|c|}
\hline \multicolumn{1}{|c|}{ EXPECTATIVA } & \multicolumn{2}{c|}{ SEMESTRE } \\
\hline Conseguir bom emprego na área & 10 Sem & 3o Sem. \\
\hline Concurso público & 2 & 9 \\
\hline Fazer Mestrado/ seguir estudando & 7 & 7 \\
\hline Reconhecimento profissional & 3 & 6 \\
\hline Ser um excelente profissional & 1 & 1 \\
\hline Professor universitário & 5 & 3 \\
\hline Melhores possíveis & 2 & 2 \\
\hline Ingressar no mercado de trabalho independente da área & 1 & 4 \\
\hline Estabilidade financeira & 5 & 1 \\
\hline Não soube ou não respondeu & 1 & 2 \\
\hline
\end{tabular}

Fonte: As autoras 
Tatiana Costa Rosa, Rosanara Pacheco Urbanetto

Uma escolha, múltiplas motivações: o caso dos estudantes do curso de arquivologia da Universidade Federal de Santa Maria

Os dados obtidos demonstram que as expectativas profissionais dos sujeitos variaram de acordo com o semestre em que se encontram. Pode-se constatar que a maioria dos estudantes do primeiro semestre do Curso de Arquivologia da UFSM, ainda não possui expectativas definidas. Sendo que 09 sujeitos mencionaram que suas expectativas estão centralizadas em concurso público, seguidos por 06 sujeitos que não souberam ou não responderam. Já os estudantes do terceiro semestre, possivelmente pelo fato de estarem no Curso há mais tempo, demonstraram-se mais conscientes sobre suas expectativas profissionais. Entre suas respostas, destacaram-se: conseguir um bom emprego na área, contando com 09 sujeitos, seguido por uma educação continuada (fazer mestrado/seguir estudando), com 07 sujeitos, concurso público e obter reconhecimento profissional, contaram com 06 sujeitos cada, respectivamente.

\section{CONSIDERAÇÕES FINAIS}

Por meio desta pesquisa, pode-se compreender alguns aspectos importantes relativos à motivações do estudantes do Curso de Arquivologia da UFSM, bem como outros fatores que estão interligados à motivações e expectativas.

O fato de o concurso público ser mencionado pelo maior número de sujeitos, quanto às suas expectativas profissionais, vem reforçar os resultados obtidos em uma de nossas pesquisas anteriores, intitulada "Perspectivas profissionais dos acadêmicos do Curso de Arquivologia da UFSM" na qual também predominou como perspectiva, ser concursado.

No que diz respeito às motivações pela escolha do Curso, predominou a opção de que os estudantes gostaram do curso e de suas disciplinas, seguida pelo baixo ponto de corte, e pela ideia da ampla oportunidade no mercado de trabalho. O que é interessante, pois este resultado vai direto com a teoria da expectativa: Motivação $=$ Expectativa $\mathrm{x}$ Instrumentalidade $\mathrm{x}$ Valor. Ou seja, isto reflete também no nível dos estudantes o qual se pode constatar que, em sua maioria, estão satisfeitos com escolha pelo Curso. 
Com a finalização desta investigação e considerando que a motivação é um dos fatores psicológicos importante para impulsionar de forma positiva o ser humano, espera-se que os resultados obtidos possam vir a contribuir com os estudantes do Curso de Arquivologia da UFSM, que poderão ter uma noção de suas motivações e das dos demais colegas e com o Núcleo Docente Estruturante (NDE) encarregado de promover a Reforma Curricular do Curso de Arquivologia da UFSM. Bem como, espera-se também trazer subsídios para novos pesquisadores acerca deste tema, e para o fortalecimento do ensino no Curso de Arquivologia da UFSM.

\section{REFERÊNCIAS}

ALARCÃO, I. Percursos de formação e desenvolvimento profissional, 1997.

CAMPOS, L. O. B. N.; MESQUITA, H. T. O ensino da Administração sob a ótica do discente. In: Encontro da ANPAD, 29, 2005, Brasília. Anais... 29 Encontro ANPAD. Brasília, 2005. CD-ROM.

DUTRA, J. S. Administração de carreiras: uma proposta para repensar a gestão de pessoas. São Paulo: Atlas, 1996.

GIL, A. C. Como elaborar projetos de pesquisa. 4. ed. São Paulo: Atlas, 2008.

IRION, P. C. Cronologia do processo de instalação dos cursos de graduação da UFSM - 1960 - 1985. Santa Maria: UFSM. Programa de Avaliação de Reforma Universitária, 1985.

MINAYO, M.C. de S. (Org.) Pesquisa social: teoria, método e criatividade. 22. ed. Rio de Janeiro: Vozes, 2003.

PIERON, H. - Dicionário de psicologia. 5. Ed. Porto Alegre: Globo, 1977.

SCHEIN, E. H. Carrrer achours: discovering your real values. Califórnia: University Associates, 1990.

UNIVERSIDADE FEDERAL DE SANTA MARIA. Histórico. Disponível em: http://sucuri.ufsm.br/ outros/historico index.php . Acesso em 20 de Maio. 2017. 
Tatiana Costa Rosa, Rosanara Pacheco Urbanetto

Uma escolha, múltiplas motivações: o caso dos estudantes do curso de arquivologia da Universidade Federal de Santa Maria

. Curso de Arquivologia. Apresentação. Disponível em:

http://w3.ufsm.br/prograd/cursos/ARQUIVOLOGIA/APRESENTAcaO.pdf .

Acesso em: 20 de maio 2017.

. Curso de Arquivologia. Projeto Pedagógico do Curso. Disponível em: http://w3.ufsm.br/prograd/cursos/ARQUIVOLOGIA . Acesso em: 20 de maio 2017.

. Centro de Ciências Sociais e Humanas. Histórico. Disponível em:

http://sites. multiweb.ufsm.br/ccsh/index.php?option=com content\&view=article \&id=3\&ltemid=2 . Aceso em: 20 de Maio 2017.

VEDOIN, A. M. R. GARCIA, O. M. C. Tendência empreendedora: perfil dos alunos do curso de arquivologia da Universidade Federal de Santa Maria. In: XIII SemeAd - Seminários em Administração, p.4, 2010, USP, São Paulo.

VROOM, V. H. Work and Motivation. Nova lorque: John Wiley, 1964.

\section{Title}

An election, multiple motivations: the case of the students of the course of Arquivologia of the Federal University of Santa Maria

\section{Abstract:}

Introduction: This investigation is centered in the motivations of the students enrolled in the first and third semesters, respectively, of the Course of Arquivologia of the Federal University of Santa Maria.

Objectives: Establish the motivations of the students by the election of the Course of Arquivologia of the UFSM; characterize the subjects, identify the factors motivationally and influencer In the election of the course and identify the professional expectations of the students in relation to the future like archivists.

Methodology: The present investigation characterizes as of cuneo descriptive, ally to a lifting, and uses the method qualiquantitativa like boarding for understanding, analysis and presentation of the results obtained.

Results: The rank etarie of the subjects that predominated is 17 to 21 years, of the feminine gender, resident in the urban zone. The half whereby the majority took knowledge of the course was by the internet. The initial interest by the election of the Course was by the low minimum note for ingress and the listing of the disciplines that integrate the current curriculum, also some students were influenced by familiars/friends. At present the majority considers satisfied with the election, remain partially with the same initial perception in relation to the Course and like future perspectives quote public contests, continued education and good employment. The students think that has to have a greater divulging of the Course and of the professionals that this spear in the market of work.

Conclusions: By means of the results obtained expects contribute with the students of the Course of Arquivologia of the UFSM so that they know his motivations and the ones of the other mates, and the ones of the other mates, and mainly collaborate with the Educational Core Structuring (NDE) of the Course of Arquivologia of the UFSM commissioned to promoter the next Reform Curricular. 
Tatiana Costa Rosa, Rosanara Pacheco Urbanetto

Uma escolha, múltiplas motivações: o caso dos estudantes do curso de arquivologia da Universidade Federal de Santa Maria

Keywords: Course of Arquivologia. Federal University of Santa Maria. Motivations. Students of Arquivologia.

\section{Titulo}

Una elección, múltiples motivaciones: el caso de los estudiantes del curso de arquivologia de la Universidad Federal de Santa Maria

\section{Resumem}

Introducción: Esta investigación está centrada en las motivaciones de los estudiantes matriculados en el primero y tercer semestres, respectivamente, del Curso de Arquivologia de la Universidad Federal de Santa Maria.

Objetivos: Establecer las motivaciones de los estudiantes por la elección del Curso de Arquivologia de la UFSM; caracterizar los sujetos, identificar los factores motivaciones e influenciadores en la elección del curso e identificar las expectativas profesionales de los estudiantes en relación al futuro como archivistas.

Metodología: La presente investigación se caracteriza de cuño descriptiva, aliada a un levantamiento, y se utiliza el método qualiquantitativo como abordaje para comprensión, análisis y presentación de los resultados obtenidos.

Resultados: El rango etaria de los sujetos que predominó es 17 a 21 años, del género femenino, residentes en la zona urbana. El medio por el cual la mayoría tomó conocimiento del curso fue por la internet. El interés inicial por la elección del Curso fue por la baja nota mínima para ingresar y el listado de las disciplinas que integran el currículo actual, también algunos estudiantes fueron influenciados por familiares/amigos. Actualmente la mayoría se considera satisfecha con la elección, permanecen parcialmente con la misma percepción inicial en relación al Curso y como perspectivas futuras citan concursos públicos, educación continuada y buen empleo. Los estudiantes creen que debe haber una mayor divulgación del Curso y de los profesionales que este lanza en el mercado de trabajo.

Conclusiones: Por medio de los resultados obtenidos se espera contribuir con los estudiantes del Curso de Arquivologia de la UFSM para que conozcan sus motivaciones y las de los demás compañeros, y principalmente colaborar con el Núcleo Docente Estructurante (NDE) del Curso de Arquivologia de la UFSM encargado de promover la próxima Reforma Curricular.

Palabras clave: Curso de Arquivologia. Universidad Federal de Santa Maria. Motivaciones. Estudiantes de Arquivologia.

Recebido: 10.03 .2017

Aceito: 10.11 .2017 